\title{
Feasibility Study of Superconducting Power Cables for DC Electric Railway Feeding Systems in View of Thermal Condition at Short Circuit Accident
}

\author{
Daisuke Kumagai $^{\mathrm{a}, *}$, Hiroyuki Ohsaki ${ }^{\mathrm{a}}$ and Masaru Tomita ${ }^{\mathrm{b}}$ \\ ${ }^{a}$ Graduate School of Frontier Sciences, The University of Tokyo, Kashiwa, Chiba 277-8561, \\ Japan \\ ${ }^{b}$ Railway Technical Research Institute, Kokubunji, Tokyo 185-8540, Japan
}

Corresponding author. Tel.: +81-4-7136-4040

E-mail address: ohsaki@k.u-tokyo.ac.jp (H. Ohsaki).

\section{Keywords:}

Superconducting power cable

Railway

Short circuit accident

Joule heating

Thermal analysis

\begin{abstract}
A superconducting power cable has merits of a high power transmission capacity, transmission losses reduction, a compactness, etc., therefore, we have been studying the feasibility of applying superconducting power cables to DC electric railway feeding systems.

However, a superconducting power cable is required to be cooled down and kept at a very low temperature, so it is important to reveal its thermal and cooling characteristics. In this study, electric circuit analysis models of the system and thermal analysis models of superconducting cables were constructed and the system behaviors were simulated. We analyzed the heat generation by a short circuit accident and transient temperature distribution of the cable to estimate the value of temperature rise and the time required from the accident. From these results, we discussed a feasibility of superconducting cables for DC electric
\end{abstract}


railway feeding systems. The results showed that the short circuit accident had little impact on the thermal condition of a superconducting cable in the installed system. 


\section{Introduction}

A superconducting power cable is expected as a future technology of power transportation by high power transmission capacity, low transmission losses, and so on. Thanks to the merits, the cable has been researched and developed actively all over the world [1-5]. While superconducting cables are mainly expected for applications in utility grid, we focus on a railway application of a superconducting cable and have been studying the feasibility of applying superconducting cables to DC electric railway feeding systems. Our previous study showed that the superconducting power cables could improve regeneration rate and system energy saving and reduce the substation output current effectively [6].

However, a high temperature superconducting (HTS) cable needs to be cooled down to a liquid nitrogen (LN2) temperature. The cable temperature increases due to heat flow through the vacuum thermal insulation layer and pressure losses in flow channels at a steady state [7]. Also, it has been concerned that the installation of superconducting cables would lead to increase of short circuit currents [8]. When a short circuit accident arises, a superconducting cable temperature will rapidly rise because of joule heating. Depending on the degree of temperature increase, it may lead to the deterioration of the power capacity and the damage caused by the pressure rise due to the boiling of LN2. Even if a short circuit accident occurs, the cable condition is required to be kept at a low temperature for the LN2 not to heat to vaporization. Then, if it takes a long time for the cable to be cooled down again and resume operations after the accident, it is difficult to introduce a superconducting cable into DC electric railway feeding systems. To reveal its thermal characteristics is quite important for the system operation.

In this study, an electric circuit analysis model of a DC electric railway feeding system and a thermal analysis model of a superconducting cable were constructed, and we analyzed the heat generation by a short circuit accident and the temperature distributions along the superconducting cables. By means of the simulation results, we discussed the feasibility of superconducting cables for DC electric railway feeding systems.

\section{Analysis method}

2.1. Thermal analysis model of a superconducting cable 
Fig. 1 shows the thermal analysis model of a superconducting cable which is based on the cable developed at Railway Technical Research Institute [9]. The cable model has a diameter of $139 \mathrm{~mm}$. Although the outermost layer of actual superconducting cables is corrosion proof layer of polyvinyl chloride (PVC), this model has only the portions on the inner side of the inner corrugated tube. The corrugated tubes including the former were assumed to be smooth tubes in the analysis. We assumed to use DI-BSCCO Type HT (CA50) tapes as HTS layers and their thermal conductivity was given to these layers [10]. Also, the values of silver and copper parameters such as heat capacity and density are used. The structural and material parameters of the model are summarized in Table I and II. This cable has two channels of LN2 such as go-flow and return-flow. A heat transfer coefficient $h$ at the boundary surface of the coolant follows the Dittus-Boelter correlation:

$$
h=0.023 R_{e}^{0.8} P_{r}^{0.4} \frac{k}{D_{e}}
$$

where $R_{e}, P_{r}, k$ and $D_{e}$ are Reynolds number, Prandtl number, thermal conductivity of the coolant, and the hydraulic diameter, respectively. A pressure drop along flow channel in a tube is calculated by Darcy-Weisbach equation:

$$
\Delta P=\lambda \frac{L}{D_{e}} \frac{\rho u^{2}}{2}
$$

where $\Delta P, \lambda, \rho$, and $u$ are pressure drop, pipe friction factor, fluid density, and mean flow velocity, respectively. Hawthorne and Von Helms reported a frictional factor formula for a corrugated pipe, which is given by [11]

$$
\lambda=D_{e}\left[1-\left(\frac{D_{e}}{D_{e}+0.438 p}\right)^{2}\right]
$$

where $p$ is the pitch of the corrugated tube. In this analysis, $p$ of former is $10 \mathrm{~mm}$ and $p$ of inner corrugated tube is $15 \mathrm{~mm}$. Three kinds of cable heat losses are assumed such as invasion from outside of a superconducting cable, pressure loss, and joule heating. The heat invasion is given to the inner corrugated tube as boundary condition. The pressure loss is given to go-flow and return-flow and the joule heating at short circuit accident is given to HTS conductor layer, HTS shield layer, Cu conductor layer and Cu shield layer. 


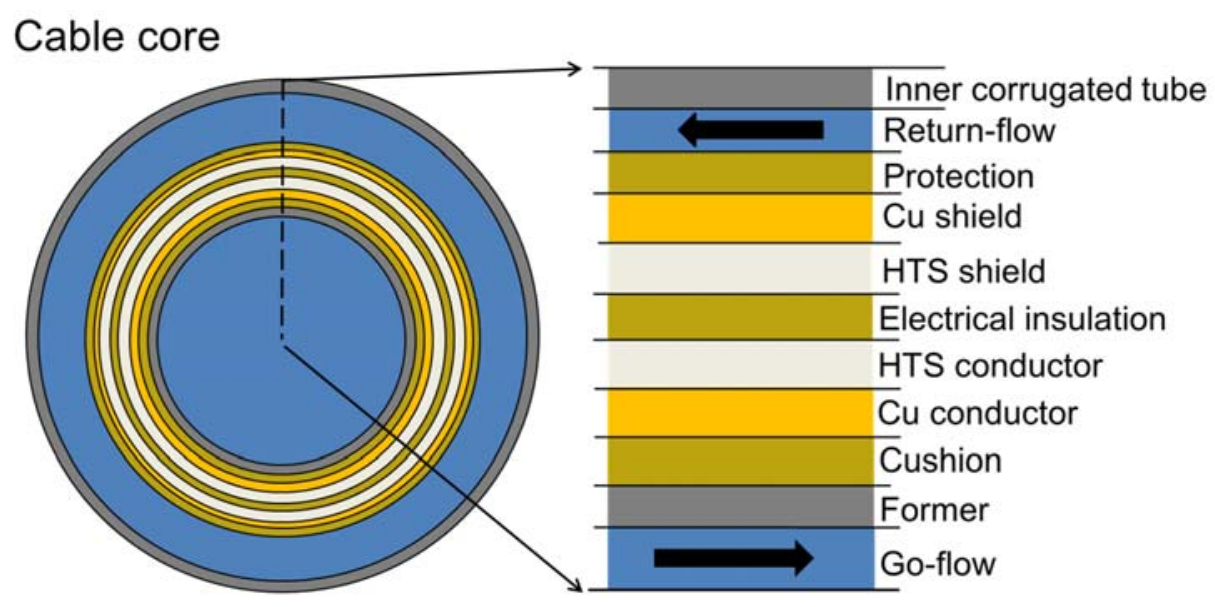

Fig. 1. Superconducting cable model for thermal analysis.

TABLE I

Structural Parameters of The Superconducting Cable Model

\begin{tabular}{lrr}
\hline \hline Layer & Material & Diameter (mm) \\
\hline Go-flow & LN $_{2}$ & 46.0 \\
\hline Former & Stainless steel & $46.0-49.0$ \\
\hline Cushion & PPLP & $49.0-54.0$ \\
\hline Cu conductor & Copper & $54.0-56.3$ \\
\hline HTS conductor & HTS & $56.3-58.6$ \\
\hline Electrical insulation & PPLP & $58.6-62.6$ \\
\hline HTS shield & HTS & $62.6-64.6$ \\
\hline Shield & Copper & $64.6-66.0$ \\
\hline Protection & PPLP & $66.0-70.0$ \\
\hline Return-flow & LN 2 & $70.0-96.0$ \\
\hline Inner corrugated tube & Stainless steel & $96.0-102$ \\
\hline \hline
\end{tabular}


TABLE II

MATERIAL PARAMETERS

\begin{tabular}{lccr}
\hline \hline Material & Thermal conductivity $(\mathrm{W} / \mathrm{mK})$ & Heat capacity $(\mathrm{J} / \mathrm{kgK})$ & Density $\left(\mathrm{kg} / \mathrm{m}^{3}\right)$ \\
\hline $\mathrm{LN}_{2}$ & 0.2 & 2000 & 808 \\
\hline Copper & 580 & 185 & 8940 \\
\hline HTS & 292 & 164 & 10054 \\
\hline Stainless Steel & 8.0 & 475 & 7850 \\
\hline PPLP & 0.25 & 1930 & 0.9 \\
\hline \hline
\end{tabular}

2.2. Circuit model of a DC electric railway feeding system

Fig. 2 shows the electric circuit analysis model of a DC electric railway feeding system. There are 5 substations (SS), which are connected by feeders and superconducting cables (SC). In this analysis, a substation was simply modeled by a set of a DC voltage source and a DC reactor, which has an inductance and a resistance. Fig. 3 shows a superconducting cable model with electric circuit. As is the case with thermal analysis model, a superconducting cable model for circuit analysis is based on the cable developed at Railway Technical Research Institute [9]. The critical current at $77 \mathrm{~K}$ is $10 \mathrm{kA}$ and a power law is used as $\mathrm{I}-\mathrm{V}$ characteristics of superconductors, represented by the following equation:

$$
V=V_{c}\left(\frac{I}{I_{c}}\right)^{n}
$$

where, $V$ and $I$ are the voltage and current respectively. $V_{c}$ is the reference voltage of $1 \mu \mathrm{V} / \mathrm{cm}$. When $I$ is under $I_{c}, n$ is 18. On the other hand, when $I$ is over $I_{c}, n$ is 12 . Also, $I_{c}$ is the critical current of the superconductor and it is given by

$$
I_{c}=I_{c 0}\left(\frac{T_{c}-T}{T_{c}-T_{o}}\right)^{\alpha}
$$


where, $T$ is the temperature and $\alpha$ is 1.5. $T_{c}$, and $T_{o}$ are the critical temperature and the environment temperature, respectively. And they are respectively $110 \mathrm{~K}$ and $77 \mathrm{~K} . I_{c o}$ is the critical current at the temperature of $T_{o}$ of $10.1 \mathrm{kA}$ at HTS conductor layer and $10.9 \mathrm{kA}$ at HTS shield layer. The resistances of stabilizer and copper layer, $R_{\text {stabilizer }}(\Omega / \mathrm{km})$, and $R_{\text {copper_layer }}(\Omega / \mathrm{km})$, have a temperature dependence. The resistance of the stabilizer in HTS conductor layer is given by

$$
R_{\text {stabilizer }}=1 /\left\{1 /\left(1.86 \times 10^{-3} T-0.043\right)+1 /\left(3.61 \times 10^{-4}+0.0561\right)\right\}
$$

The resistance of the stabilizer in HTS shield layer is given by

$$
R_{\text {stabilizer }}=1 /\left\{1 /\left(1.62 \times 10^{-4} T-0.0374\right)+1 /\left(3.13 \times 10^{-4}+0.0487\right)\right\}
$$

The resistance of the copper layer on the part of HTS conductor layer is given by

$$
R_{\text {copper_layer }}=1.08 \times 10^{-4} T+0.0167
$$

The resistance of the copper layer on the part of HTS shield layer is given by

$$
R_{\text {copper_layer }}=1.23 \times 10^{-4} \mathrm{~T}+0.0191
$$

The stabilizer is assumed as parallel structure of silver and copper. The parameters of the circuit model are summarized in Tables III. We assumed a dead short circuit accident near SS5 and the arc voltage and resistance of the fault point were set to zero.

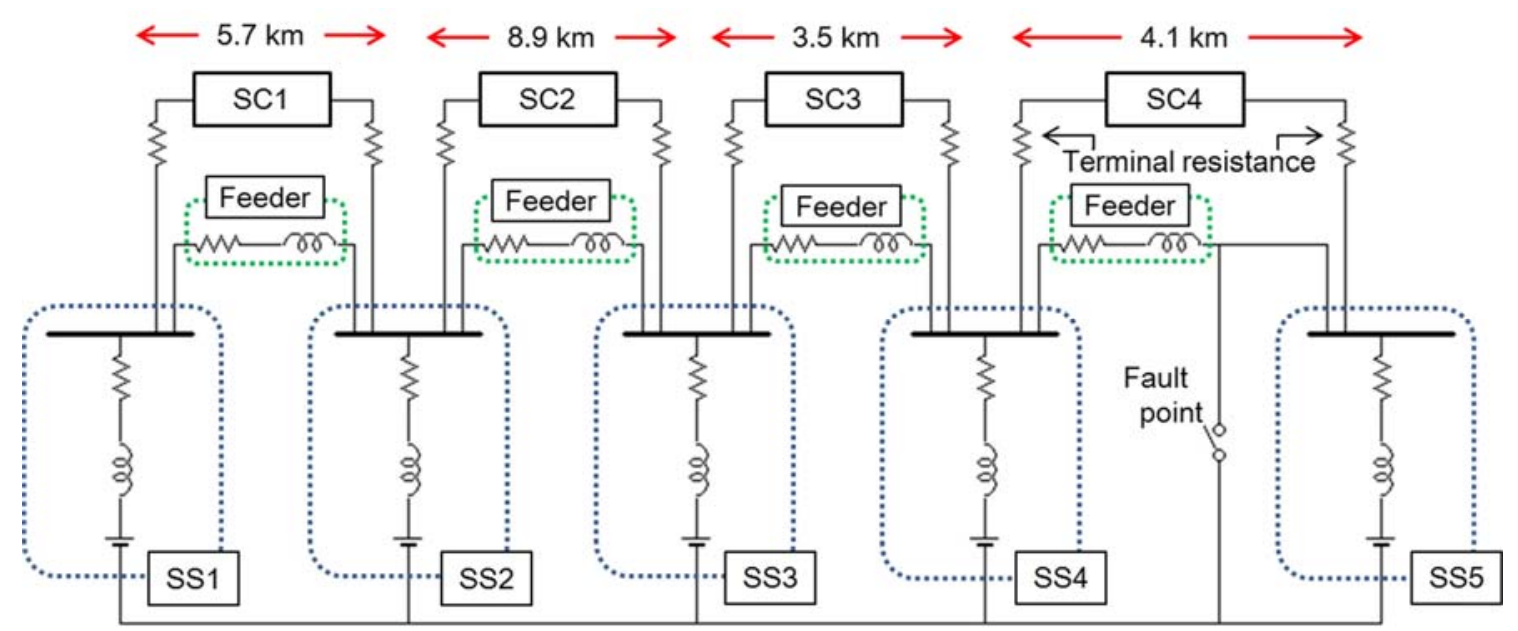

Fig. 2. Electric circuit model of a DC electric railway feeding system. 


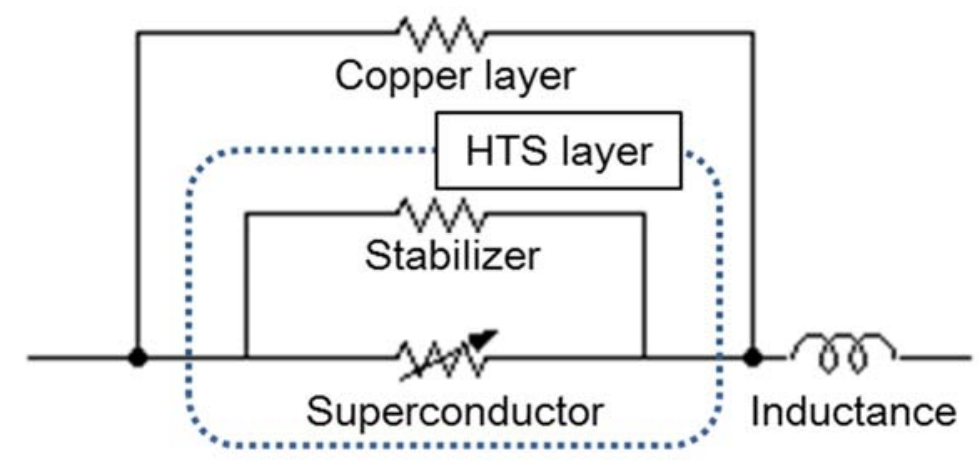

Fig. 3. Electrical circuit model of a superconducting cable.

TABLE III

Parameters of The Feeding System Model

\begin{tabular}{|c|c|c|}
\hline \multirow{3}{*}{ Substation } & DC voltage source $(\mathrm{V})$ & 1590 \\
\hline & Internal resistance $(\Omega)$ & 0.001 \\
\hline & Inductance $(\mathrm{mH})$ & 1.1 \\
\hline \multirow{2}{*}{ Feeder } & Resistance $(\Omega / \mathrm{km})$ & 0.0333 \\
\hline & Inductance $(\mathrm{mH} / \mathrm{km})$ & 1.1 \\
\hline \multirow{5}{*}{ Superconducting cable } & Superconductor & Eq. (4) and (5) \\
\hline & Stabilizer $(\Omega / \mathrm{km})$ & Eq. (6) and (7) \\
\hline & Copper layer $(\Omega / \mathrm{km})$ & Eq. (8) and (9) \\
\hline & Inductance $(\mathrm{mH} / \mathrm{km})$ & 0.0336 \\
\hline & Terminal resistance ( $\mu \Omega /$ each) & 10 \\
\hline
\end{tabular}

\subsection{Operational Conditions}

To simplify the analysis, we assumed that SC1, SC2 and SC3 were uniformly $70 \mathrm{~K}$ and the thermal analysis was applied to only SC4. SS4 and SS5 are connected by two superconducting cables of $2.05 \mathrm{~km}$ each length. Here, refrigerators and pumps are installed at both ends of the superconducting cable and another refrigerator is installed at the intermediate point of SC4. The cooling system is designed to keep LN2 temperature under $77 \mathrm{~K}$. The coolant pumped from these points is kept at $70 \mathrm{~K}$. The flow rate of coolant and the differential 
pressure generated by the pump are set to $30 \mathrm{~L} / \mathrm{min}$ and $0.36 \mathrm{MPa}$, based on the discussion in [12]. The heat invasion is $0.82 \mathrm{~W} / \mathrm{m}$ and the pressure losses in go-flow and return- flow are calculated as $0.12 \mathrm{~W} / \mathrm{m}$ and $0.093 \mathrm{~W} / \mathrm{m}$, respectively. Although a fault current is generally cut off within several milliseconds to several ten milliseconds by circuit breakers, considering a failure to open, the fault current is assumed to be cut off 0.3 seconds after the fault accident occurred in this analysis. The joule heating of a superconductor and a stabilizer shown in Fig. 3 is given to HTS layers (Fig. 1) and that of a copper layer shown in Fig. 3 is given to $\mathrm{Cu}$ layers (Fig. 1). Although there are AC losses and coupling losses, they are much smaller than joule losses by a short circuit accident. Therefore, we assumed that they could be ignored in the analysis. The cable model for the thermal analysis model (Fig. 1) is divided into 41 parts of $50 \mathrm{~m}$ each length and the cable model for the circuit analysis is a circuit of series of 41 elements of $50 \mathrm{~m}$ each length (Fig. 3). Then each corresponding element is made to have temperature and joule heating in common. The thermal analysis and the circuit analysis of the superconducting cable are carried out using the model and the conditions explained above.

\section{Analysis Results}

Fig. 4 shows the superconducting cable temperature distribution along the go-flow and the return-flow at the steady state. The temperature rises at even steady state due to the heat invasion from the outside of the cable and pressure losses. Since the heat exchange occurs between the go-flow and return-flow, the temperature is the highest in the middle section of the cable. Fig. 5 shows the waveforms of fault currents flowing through the superconducting cables. The fault current through SC4 rises up to about $35 \mathrm{kA}$ without circuit breakers, so it is required to install circuit breakers to cut off the current. Fig. 6 shows the waveforms of fault currents flowing through HTS layers of SC4. According to the result of the test on DI-BSCCO Type HT (CA50) tapes [9], the current up to $3 I_{c}$ for $100 \mathrm{~ms}$ doesn't lead to the degradation of $I_{c}$. Therefore it is predictable that the superconducting cable is safe for $100 \mathrm{~ms}$. It is required to conduct over-current tests not only on tapes but also on cables for the future. Fig. 7 shows the temperature transition of superconducting layers. As the cable temperature is raised due to the short circuit current, the resistance of HTS and copper layers are also raised. It resulted in the decrease of fault currents. The fault currents generate a joule heating and the 
heat is transferred from HTS and copper layers to go-flow and return-flow. Fig. 8 shows the temperature transition in go-flow and return-flow of SC4. The temperatures at $1.09 \mathrm{~km}$ in go-flow and at $0.958 \mathrm{~km}$ in return-flow from the terminal of SC4 are shown, where the temperatures of LN2 are the highest along flow channels. The temperatures of LN2 were kept low after a short circuit accident.

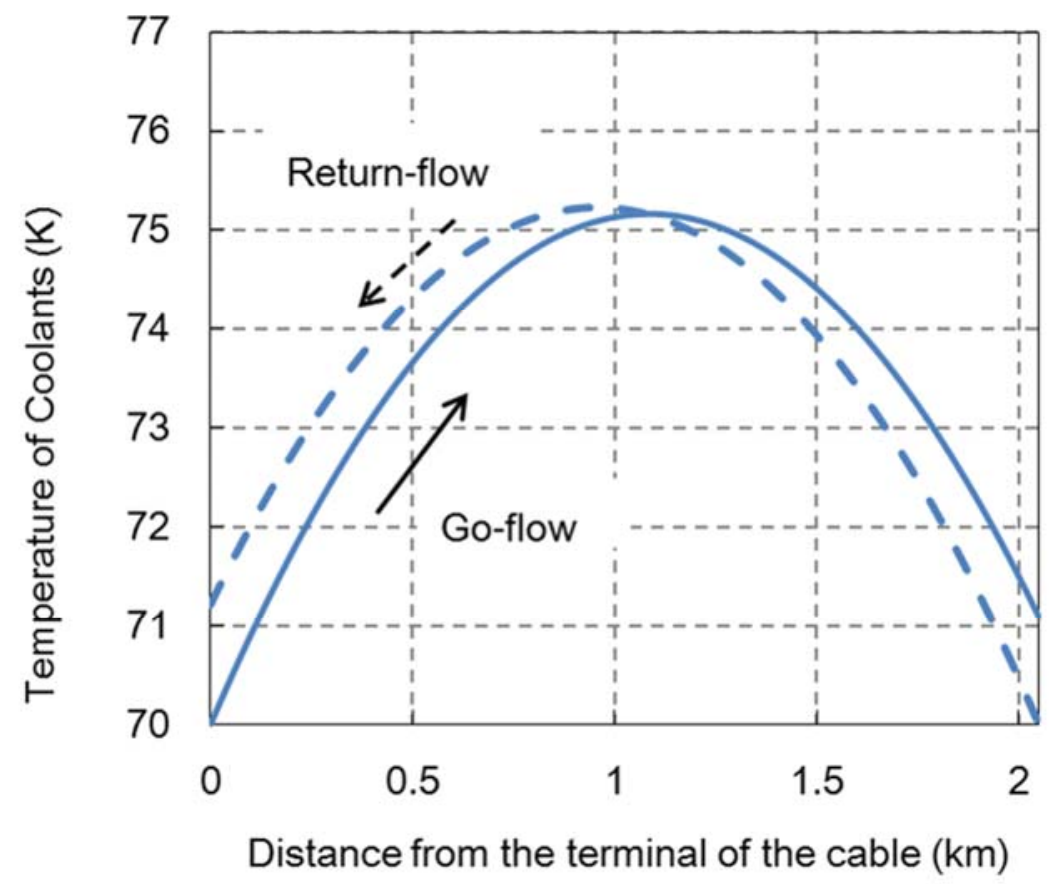

Fig. 4. Temperature distribution of coolants in the superconducting cable at the steady state. 


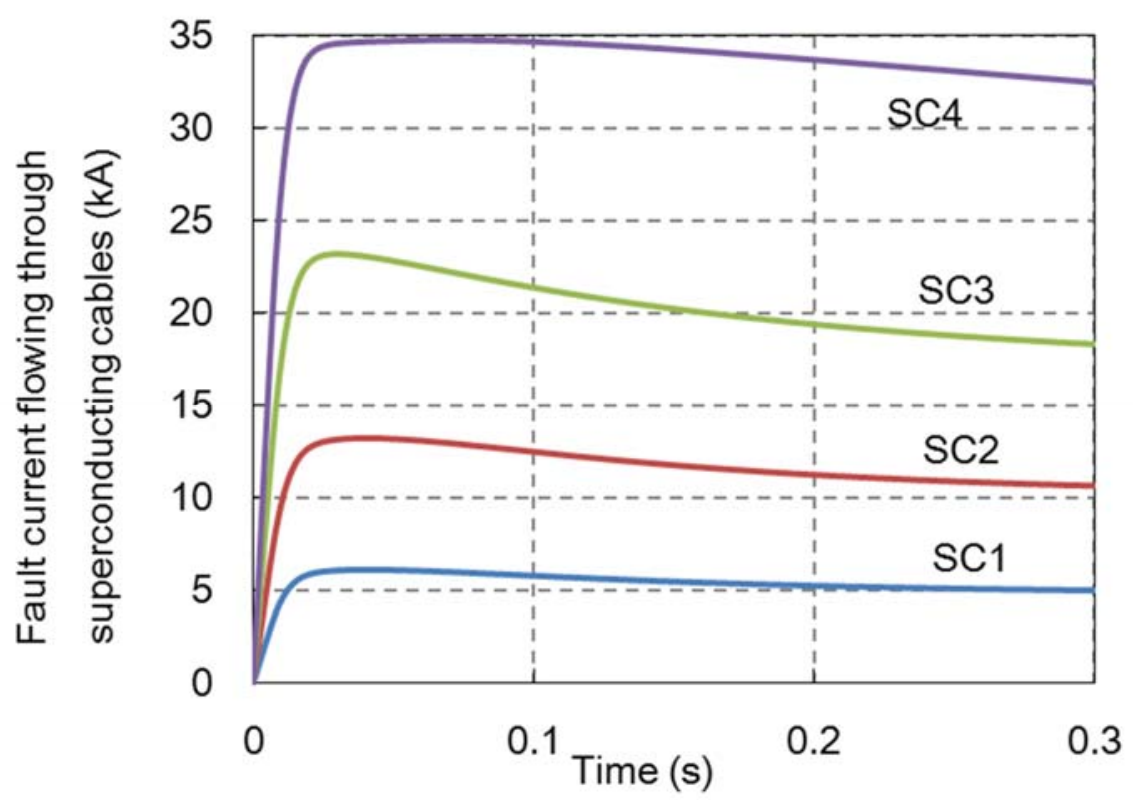

Fig. 5. Fault currents flowing through superconducting cables at short circuit accident.

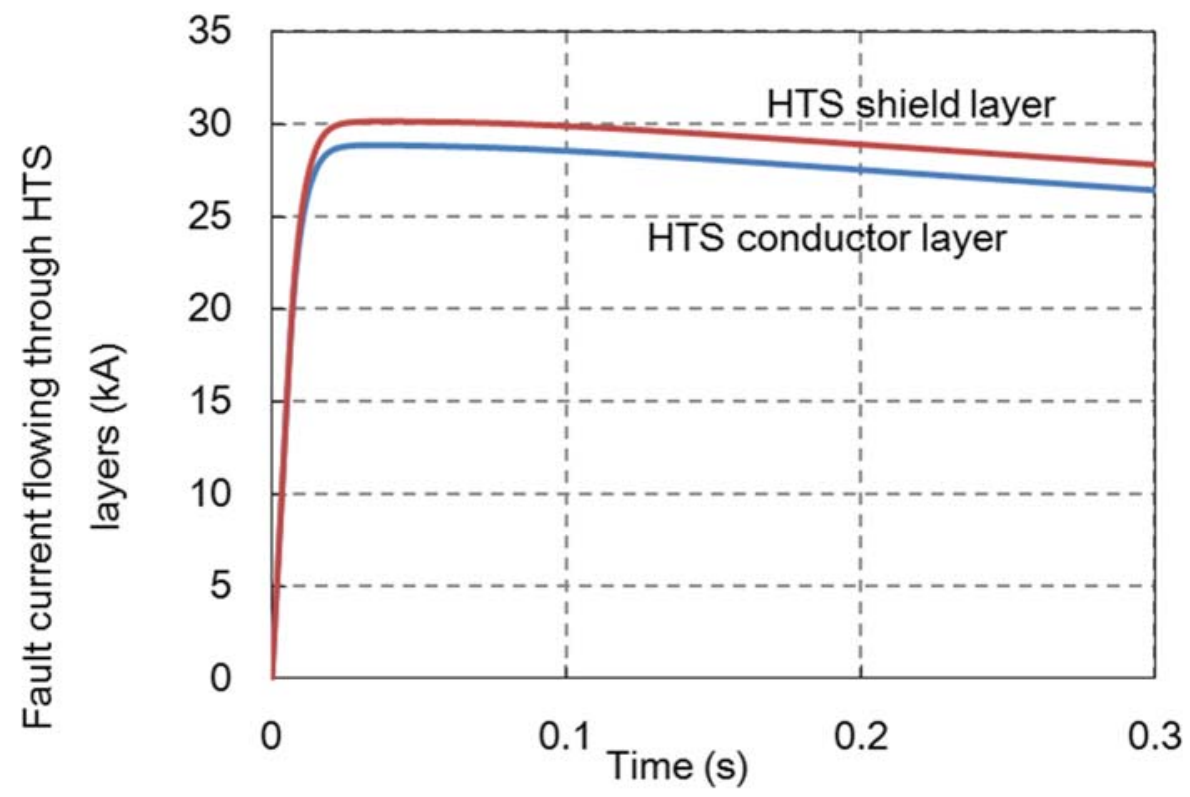

Fig. 6. Fault currents flowing through HTS layers in SC4 at short circuit accident. 


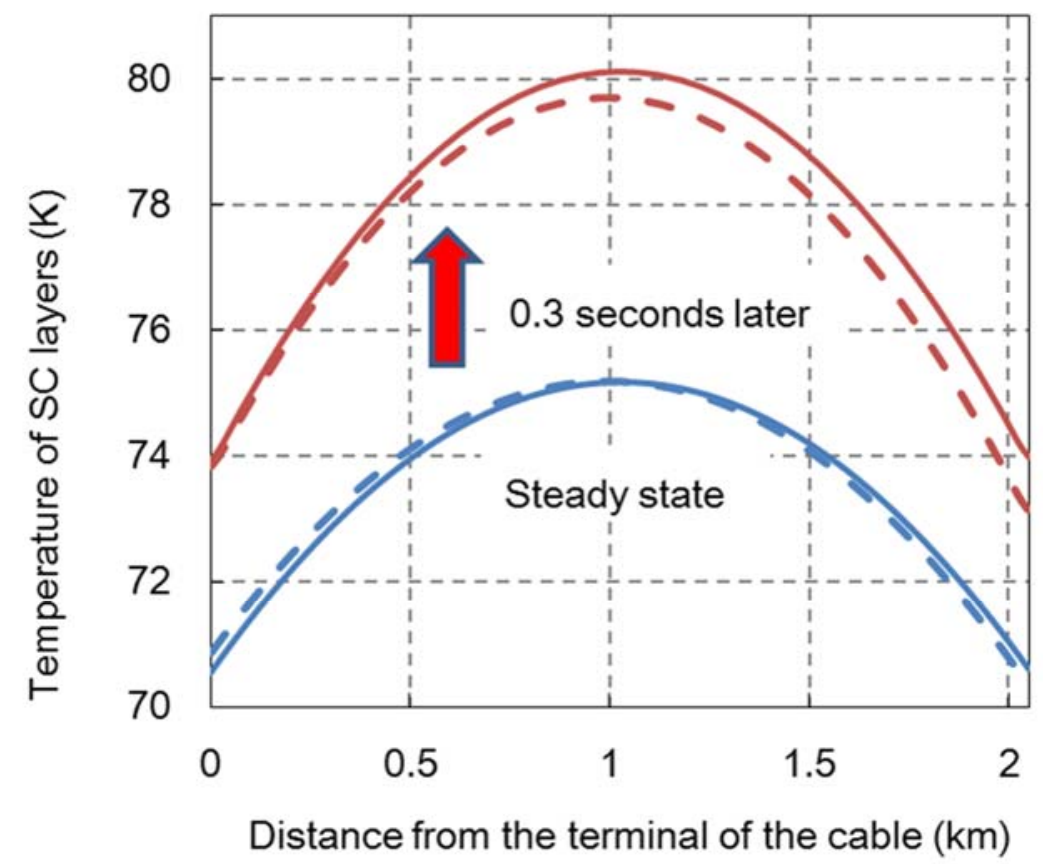

Fig. 7. Temperature distribution and transition of superconducting layers in a superconducting cable.

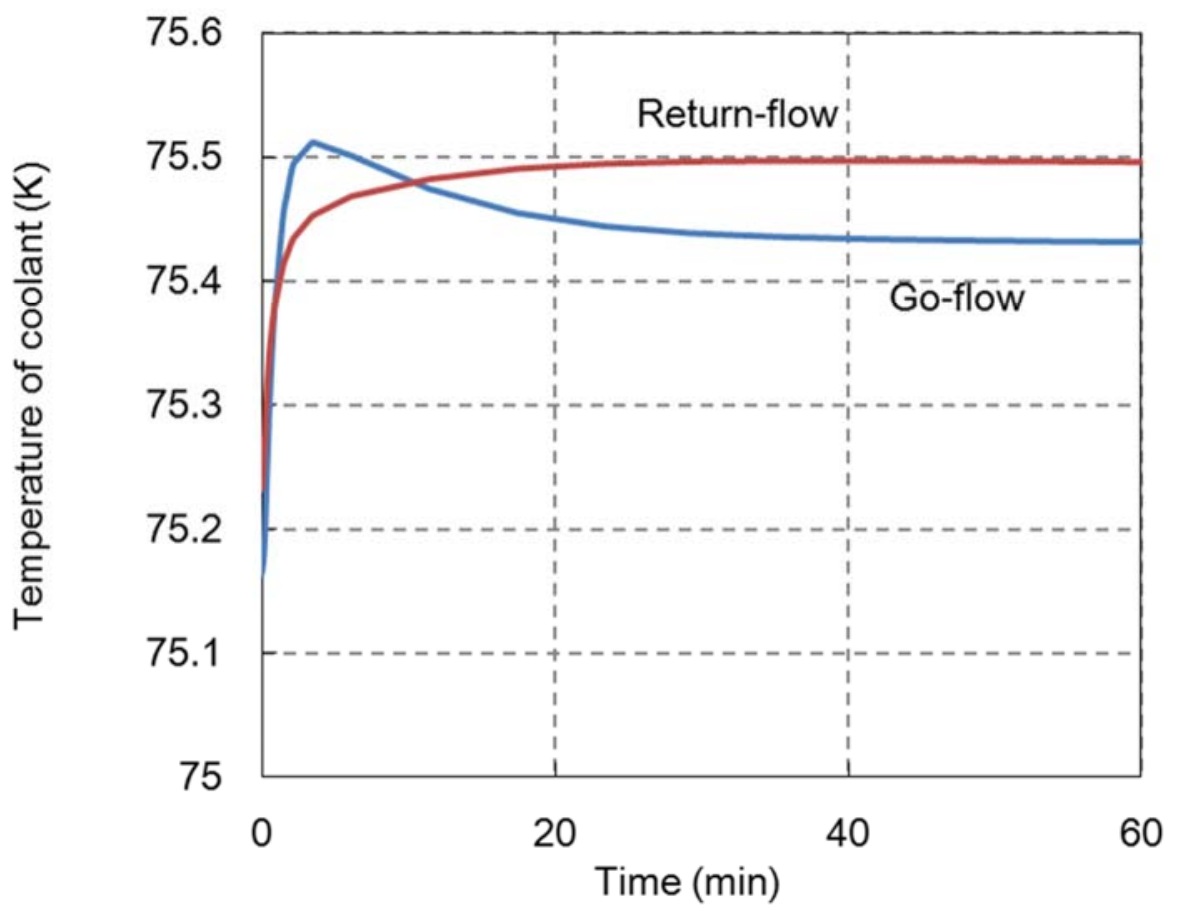

Fig. 8. Temperature transition in go-flow and return- flow. The focused points are at $1.09 \mathrm{~km}$ 
in go-flow and at $0.958 \mathrm{~km}$ in return-flow from the terminal of SC4.

\section{Conclusion}

In this study, we investigated a feasibility of superconducting cables for DC electric railway feeding systems by analyzing a thermal condition at short circuit accident. The result shows that the cable temperature is not so much raised by the short circuit accident for 0.3 seconds, so the superconducting cable is kept in safety and takes no time to resume operation after the accident. In order to put superconducting cables into practical use in the future, it is required to make them longer. It is considered that the lengthening of them will enhance the current-limiting effect that they have. Therefore, if superconducting cables are adequately cooled down at steady state, there is little need to take short circuit accidents into account for a cooling system. Further analysis whose condition is changed such as the cooling system, duration time of short circuit, etc. is required to the next step. 


\section{Acknowledgement}

This work was supported by the Japan Science and Technology Agency, JST, under the Strategic Promotion of Innovative Research and Development Program.

\section{References}

[1] M. Stemmle, F. Merschel, M. Noe, and A. Hobl, “AmpaCity-Advanced superconducting medium voltage system for urban area power supply,” in Proc. IEEE PES TD Conf. Ехро., 2014, pp. 1-5.

[2] M. Daibo, K. Watanabe, K. Akashi, H. Hidaka, M. Nagata, M. Yoshida, Y. Iijima, M. Itoh, T. Saitoh, O. Maruyama, and T. Ohkuma: "Development of a 66 kV-5 kArms Class HTS Power Cable Using REBCO Tapes With High Critical Current,” IEEE Trans. Appl. Supercond., vol.25, no.3, Jun. 2015, Art. ID. 5402105.

[3] T. Nakano, O. Maruyama, S. Honjo, M. Watanabe, T. Masuda, M. Hirose, M. Shimoda, N. Nakamura, H. Yaguchi and A. Machida: "Long-term operating characteristics of Japan’s first in-grid HTS power cable,” Physica C, vol. 518, pp. 126-129, Nov. 2015.

[4] Philip C. Michael, Leslie Bromberg, Anthony J. Dietz, Kenneth J. Cragin, and Calman Gold: “Design and Test of a Prototype 20 kA HTS DC Power Transmission Cable,” IEEE Trans. Appl. Supercond., vol.25, no.3, Jun. 2015, Art. ID. 5401005.

[5] J. H. Lim, H. S. Yang, S. H. Sohn, S. W. Yim, S. Y. Jung, S. C. Han, H. W. Kim, Y. H. Kim, and S. D. Hwang: "Cryogenic System for 80-kV DC HTS Cable in the KEPCO Power Grid,” IEEE Trans. Appl. Supercond., vol.25, no.3, Jun. 2015, Art. ID. 5402804.

[6] H. Ohsaki, Z. Lv, N. Matsushita, M. Sekino, T. Koseki, and M. Tomita, "Superconducting power cable application in DC electric railway systems,” IEEE Trans. Appl. Supercond., vol. 23, no. 3, Jun. 2013, Art. ID. 3600705.

[7] H. Ohsaki, D. Kumagai, and M. Tomita: “Thermal and Cooling Characteristic Analysis of a Superconducting DC Power Cable for Railway Application,” IEEE Trans. Appl. Supercond., vol.25, no.3, Jun. 2015.

[8] K.Qian, H. Ohsaki, and M. Tomita: "Fault Current Analysis of DC Electric Railway Feeding Systems using Superconducting Power Cables,” 2014 17th International Conference on Electrical Machines and Systems, pp. 261-266, Oct. 2014. 
[9] M. Tomita, M. Muralidhar, K. Suzuki, Y. Fukumoto, and A. Ishihara: "Development of 10 kA high temperature superconducting power cable for railway,” Journal of Applied Physics, vol. 111, no. 6, pp. 063910-1-063910-4, Mar. 2012.

[10] T. Naito, H. Fujishiro, and Y. Yamada, "Thermal conductivity and thermal dilatation commercial BSCCO (DI-BSCCO) tapes,” IEEE Trans. Appl. Supercond., vol. 19, pp. 3034-3036, Jun. 2009.

[11] K. Ohira, J. Okuyama, K. Nakagomi, and K. Takahashi, "Pressure drop of slush nitrogen flow in converging-diverging pipes and corrugated pipes,” Cryogenics, vol. 52, no. 12, pp. 771-783, Dec. 2012.

[12] M. Ohya, H. Yumura, M. Watanabe, Y. Ashibe, H. Takigawa, H. Ito, T. Minamino, T. Nishimura, T. Masuda, S. Honjo, T. Mimura, Y. Kito and Y. Noguchi, “Japan’s First Operation of High-Temperature Superconducting Cable Systems in Live Grids (High-Temperature Superconducting Cable Demonstration Project),” SEI Technical Review, no. 70, pp. 84-93, 2010. 